\title{
Het opstandige geweten
}

\author{
J.C. den Hollander*
}

\section{Inleiding}

De reeks Ontmoetingen opende in 1995 met een terugblik van Professor Goudsmit op veertig jaar Lutje P.J.G. ${ }^{1}$ Hoewel er alle reden tot trots en tevredenheid was, eindigde Goudsmit zijn 'lutje geschiedenis' met een zorgelijke vooruitblik op het nieuwe millennium. Mondiale problemen zoals de verkwisting van grondstoffen, de overbevolking en de vergroting van de kloof tussen arm en rijk zouden volgens hem onvermijdelijk leiden tot meer migratie, armoede- en welstandscriminaliteit en internationaal terrorisme. Crimineel gedrag vormt immers een spiegel van wat er in de samenleving leeft: 'wordt de samenleving harder dan wordt de criminaliteit dat ook'. Anno 2005 kunnen we vaststellen dat de zorgen van Goudsmit terecht waren. De stemming is in tien jaar tijd bepaald grimmig geworden, onder invloed van dreigende terreuracties en twee geruchtmakende moordaanslagen op publieke personen. Goudsmits oproep aan het Lutje om een bijdrage te blijven leveren aan de maatschappelijke dialoog is daarom actueler dan ooit.

Vooral de dialoog tussen islamitische en niet-islamitische Nederlanders staat ernstig onder druk. Voor veel mensen is bijvoorbeeld onduidelijk in hoeverre de moord op Theo van Gogh op 2 november 2004 moet worden toegerekend aan de individuele dader Mohammed B. dan wel aan de islamitische geloofsovertuiging die hij zei te verdedigen. Natuurlijk dreigt hier een groot gevaar van generalisatie, waarbij de daad van één persoon wordt toegeschreven aan een hele groep. Daar moet tegen gewaarschuwd worden, want een meerderheid van de moslims keurt dit soort fundamentalistische geweldda-

* Jaap den Hollander is docent moderne geschiedenis aan de Rijksuniversiteit Groningen.

1 W.Goudsmit, '40 jaar "Lutje P.J.G.", een lutje geschiedenis', in W.F. van Hattum, A.W.M. Mooij, K. van Tuinen, ed., Ontmoetingen. Voordrachtenreeks van het Lutje Psychiatrisch-Juridisch Gezelschap 1 (z.p. 1995), p. 7-21. 
den vermoedelijk ook af. Maar de behoefte om het gevaar te bezweren moet ons niet de ogen doen sluiten voor het feit dat de grens tussen religieuze overtuiging en recht voor de islamitische gemeenschap zelf een probleem vormt.

We moeten hierbij bedenken dat het christelijke Europa in het verleden ook grote moeite heeft gehad met het onderscheid tussen forum internum en forum externum, zoals de traditionele kerkrechtelijke formulering luidt. In de zestiende en zeventiende eeuw bedreven zowel katholieken als protestanten talloze terreuracties en andere politieke gewelddadigheden met een beroep op hun religieuze overtuiging en geweten. We hoeven maar te denken aan de Nederlandse opstand tegen de 'tiran' Filips II of aan de grote beloning die deze uitloofde aan de moordenaar van Willem van Oranje. Het lijkt daarom nuttig te bezien hoe de moderne opvattingen over geweten en recht zich hebben ontwikkeld uit de vroegmoderne ideeën over opstand en tirannenmoord. Dit geeft ons misschien wat meer inzicht in de motieven van een 'overtuigingsdader' als Mohammed B. en in de problemen die de moslimgemeenschap heeft met de beoordeling van zulke zelfbenoemde strijders voor het geloof.

\section{Het geweten}

Tegenwoordig vatten wij het geweten op als een hoogst individuele eigenschap, maar dat is niet altijd zo geweest, zoals de etymologie ons kan leren. Het woord 'geweten' is ontleend aan het Latijnse 'conscientia', dat letterlijk samen-weten betekent. Opvallend hieraan zijn twee dingen. Ten eerste het feit dat er sprake is van 'scientia' of weten. Kennelijk werd kennis van goed en kwaad ooit opgevat als een wetenschap waaraan waarheidseisen kunnen worden gesteld. Er was dus nog geen sprake van 'waarden', die subjectief worden gekozen. Het tweede dat opvalt is het voorvoegsel 'con' of samen. Dit suggereert dat we te maken hebben met een gedeelde kennis, die alle mensen van nature bezitten. Ieder mens zou met andere woorden in zich zelf na kunnen gaan wat van nature juist en onjuist is. Het geweten kan volgens deze redenering worden opgevat als een criterium om de rechtvaardigheid van wetten te beoordelen. Dat laatste is iets wat het recht zelf niet kan. Het positieve recht stelt vast wat rechtmatig en onrechtmatig is, maar raakt onmiddellijk verstrikt in een paradox bij de beantwoording van de vraag of dat onderscheid zelf te recht is. Het is dezelfde soort paradox waarop logici stuiten wanneer zij zich afvragen of het onderscheid tussen waar en onwaar 
zelf ook waar is. Het aanbrengen van niveauonderscheidingen is een beproefd middel om dit soort paradoxen op te lossen en daarom hebben juristen in het verleden vaak hun toevlucht genomen tot het 'hogere' criterium van het natuurrecht. Deze strategie werkt echter alleen, zolang men aanneemt dat het natuurrecht inderdaad objectief kenbaar is voor iedereen.

Het is niet mijn bedoeling om hier het oude debat over het natuurrecht op te rakelen, maar er moet wel even op worden gewezen om het thema van de overtuigingsdader in een historisch perspectief te plaatsen. ${ }^{2}$ Dit thema heeft immers betrekking op mensen die hun eigen overtuiging of geweten boven de bestaande rechtsorde stellen. Het maakt hierbij verschil vanuit welke kant men de zaak bekijkt. Beziet men de zaak vanuit een traditioneel religieus en/of natuurrechtelijk perspectief, dan zou men in bepaalde omstandigheden kunnen spreken over vrijheidsvechters of strijders voor een hoger ideaal. Dit is het beeld dat wij bijvoorbeeld nog koesteren van de calvinistische geuzen uit de zestiende eeuw. Bekijkt men de zaak vanuit een positiefrechtelijk perspectief dan blijft slechts 'de overtuigingsdader' over. De soevereine staat die na de godsdienstoorlogen ontstond duldt geen inbreuk meer van hogere principes die niet uitdrukkelijk door hem zelf zijn erkend. Er worden wel uitzonderingen gemaakt voor 'gewetensbezwaarden' die zich verzetten tegen bijvoorbeeld de dienstplicht of gedwongen koepokinentingen, maar het gaat daarbij altijd om een erkenning van de individuele gewetensnood en niet om de inhoudelijke argumenten waarop de persoon in kwestie zich beroept.

Vergeleken met de vroegmoderne tijd is de staat zo machtig geworden dat hij zich wel enige tolerantie kan veroorloven. Die tolerantie is bovendien duidelijk functioneel, omdat zij escalatie van conflicten helpt voorkomen. We moeten het recht op gewetensvrijheid dan ook functionalistisch bekijken. In tegenstelling tot wat men vaak denkt, ligt de betekenis ervan niet zo zeer in het toestaan als wel in het verhinderen. Ogenschijnlijk gaat het er om dat mensen in staat worden gesteld volgens hun geweten te handelen en tot op zekere hoogte is dat ook zeker het geval. Maar de eigenlijke functie van het grondrecht is juist te verhinderen dat men dit gaat doen. Als mensen echt naar hun geweten gaan handelen, kunnen er namelijk rare dingen gebeuren. Daarom is het verstandig escalatie te voorkomen. Door toe te geven op een beperkt terrein kan worden verhinderd dat de gewetensbezwaarde doorslaat

2 Zie hiervoor ook J.M. Reijntjes, 'De overtuigingsdader en het recht', in A.H. Klip, A.L. Smeulers, M.W. Wolleswinkel, ed., KriTies. Liber amicorum et amicarum voor prof. $m$ r. E. Prakken (Deventer 2004), p. 235-245. 
naar een eenmansoorlog tegen de staat. Deze gedachte, die ontleend is aan de Duitse rechtssocioloog Niklas Luhmann, verdient een nadere toelichting. ${ }^{3}$ Luhmann stelt voor het geweten functionalistisch op te vatten als een vorm van identiteitsbewaking. Het heeft dan dezelfde soort functie als eer, met dit verschil dat het bij het geweten vooral om de individuele identiteit gaat en bij eer om de sociale. Erekwesties doen zich vooral voor in traditionele maatschappijen met vaste rolpatronen, de zogenaamde schaamteculturen. Maar ook in de moderne maatschappij spelen ze nog wel degelijk een belangrijke rol, wanneer we bijvoorbeeld denken aan het leger of de wetenschap. Toch gaat onze grootste zorg tegenwoordig uit naar het individuele management van rolwisselingen en rolconflicten. Omdat het geweten hierbij een belangrijke plaats inneemt spreekt men in verband met de moderne maatschappij wel over een schuldcultuur. Zo moeten veel mensen tegenwoordig schipperen om tegelijk een goede ouder en een goede werknemer te zijn. Dat kan schuldgevoelens opleveren, zoals vooral vrouwen met een parttime baan vaak ondervinden. Gelukkig blijft de schade meestal beperkt. Maar er zijn ook situaties waarin één bepaalde handeling een compleet rollenrepertoire in diskrediet brengt. Men kan dan bijvoorbeeld denken aan de beroemde professor bij wie plagiaat wordt ontdekt of aan de trouwe echtgenote die één keer vreemd gaat en uitgerekend dan door haar jaloerse man wordt betrapt. In zulke situaties is een identiteitscrisis moeilijk te vermijden en zit er vaak weinig anders op dan een nieuw leven te beginnen of, wat soms ook voorkomt, het oude maar helemaal te beëindigen. Het probleem schuilt hier in een rollenclustering die het gevaar van een dominoeffect met zich meebrengt. Omdat het geweten zo'n massale uitval van zekerheden moeilijk kan verwerken, kunnen mensen overgaan tot desperate handelingen. Dat is een bedreiging voor de maatschappij en daarom zijn er sociale structuren die verhinderen dat mensen naar hun geweten gaan handelen.

Belangrijk is in de eerste plaats de aanwezigheid van handelingsalternatieven. Daar wordt ruimschoots in voorzien. Dezelfde maatschappelijke complexiteit die mensen zo belast zorgt tevens voor verlichting. Een voorbeeld is de bureaucratie. Er wordt weliswaar veel geklaagd over de nadelen van complexe organisaties, maar een voordeel is dat we er vrijelijk in en uit

3 Niklas Luhmann, 'Die Gewissensfreiheit und das Gewissen' (1965), Ausdifferenzierung des Rechts: Beiträge zur Rechtssoziologie und Rechtstheorie. (Frankfurt 1981) 326-360 en idem, 'Die Funktion der Gewissensfreiheit im öffentlichen Recht', in: Funktion des Gewissens im Recht. Schriften der Evangelischen Akademie in Hessen und Nassau, nr. 86 (Frankfurt am Main 1970), p. 9-22. 
kunnen stappen. Anders dan de dienstmeisjes en landarbeiders in de negentiende eeuw zitten we niet meer in een semi-feodale dienstverhouding vast aan één werkgever. Een tweede structuur die het geweten ontlast is de depersonalisatie van veel handelingen en contacten. Ook hier is sprake van een ambivalent verschijnsel, dat ons leven tegelijk zwaarder en lichter maakt. Zo moeten heel wat mensen in dienst van organisaties dingen doen waar ze zelf niet achter staan, zoals asielzoekers uitzetten, werknemers ontslaan, demonstranten verjagen of vijanden doodschieten. Dat lukt vaak alleen maar wanneer ze zogezegd een knop om kunnen draaien. In de derde en laatste plaats moet worden gewezen op het reeds vermelde recht van gewetensvrijheid. De ambivalentie is hier dat mensen worden gemanipuleerd zonder dat ze in hun waarde en vrijheid worden aangetast. Zo worden gewetensbezwaarden niet van de mogelijkheid beroofd om naar hun geweten te handelen, maar ze worden er wel met zachte hand van afgehouden. Wie wil kan zoals Michael Kohlhaas een eenmansoorlog tegen het gezag beginnen, maar in de praktijk nemen de meeste mensen genoegen met vervangende plantsoen- of archiefarbeid.

Hebben Europeanen het al moeilijk met de eisen van de moderne maatschappij, voor immigranten geldt dat natuurlijk nog sterker. Aanpassing aan een andere cultuur levert sowieso identiteitsproblemen op, omdat men met zijn eigen cultuur ook een stuk van zich zelf opgeeft. Dat geldt vooral voor immigranten uit traditionele samenlevingen, waarin de individuele identiteit nog sterk afhankelijk is van vaste sociale rollen. Het probleem van rollenclustering, waar zojuist op werd gewezen, is hier levensgroot aanwezig. Wanneer immigranten - en dan gaat het meestal om de tweede generatie tussen twee culturen in komen te staan, zit er vaak niets anders op dan een nieuwe identiteit te creëren. We zien dat bijvoorbeeld goed bij nationalistische leiders uit de negentiende en twintigste eeuw. Zo beschrijft de Indiase leider Nehru, die van 1905 tot 1912 in Engeland studeerde, in zijn autobiografie hoe hij zich noch in Engeland noch in India echt thuis voelde. ${ }^{4}$ Vaak verschafte een persoonlijke identiteitscrisis zulke politici de drive die nodig was om een nieuwe natie te creëren. Het lijkt er op dat het fundamentalisme voor jonge moslims een zelfde soort functie heeft.

Wanneer we het handelen van overtuigingsdaders als Mohammed B. willen begrijpen, moeten we niet alleen op motieven maar ook op motiveringen

4 'I have become a queer mixture of the East and the West, out of place everywhere, at home nowhere. ...I am a stranger, an alien in the West. But in my own country also, sometimes, I have an exile's feeling'. Jawaharlal Nehru, Toward Freedom: Autobiography (New York 1941), p. 353. 
letten. Hiervoor is enig inzicht vereist in zowel de moderne als de traditionele opvatting van het geweten. De moderne, functionalistische opvatting van het geweten zegt iets over persoonlijke motieven. Zij kan bijvoorbeeld duidelijk maken waarom sommige jonge moslims zich tot desperado's ontwikkelen en andere niet. Persoonlijke identiteitsproblemen zullen daarbij vaak een hoofdrol spelen. Deze verklaring is echter ontoereikend, omdat niet alle jonge moslims met identiteitsproblemen zich in de jihad storten. Bovendien kan men de zelfuitleg van mensen niet botweg negeren. Daarom moet ook worden gekeken naar de motivering die een overtuigingsdader zelf geeft. Dat vereist enig begrip van de traditionele gewetensopvatting, die schending van de bestaande rechtsorde uit naam van 'hogere' principes rechtvaardigt. Aangezien deze opvatting voor ons tamelijk vreemd is geworden, is het misschien nuttig een blik op de geschiedenis van de opstandsleer te werpen.

\section{Het recht van opstand}

Voordat het moslimfundamentalisme zich in de jaren 1980 breed begon te maken hebben veel regimes in het Midden-Oosten geëxperimenteerd met de westerse geloofsartikelen van het nationalisme en het socialisme. Dat heeft de bevolking weinig meer opgeleverd dan dictaturen en daarom is het begrijpelijk dat velen zich tenslotte gevoelig toonden voor de boodschap van de Salafiyya-beweging, die een terugkeer naar de tijd van de Profeet preekte. West-Europeanen konden dit verschijnsel tot voor kort afdoen als een probleem van de islamitische landen, maar door de grootschalige immigratie van moslims hebben zij er nu ook zelf rechtstreeks mee te maken gekregen. Het is dus belangrijk om het fundamentalisme goed te begrijpen. Dit vereist ondermeer, dat we het verschijnsel niet verwarren met traditionalisme. Puriteinen die terug willen keren naar de bron van het geloof verwerpen in het algemeen gesproken immers juist de traditie. Dat gold bijvoorbeeld voor de protestanten in de zestiende eeuw, die zich met het vroege christendom identificeerden en de traditie van de rooms-katholieke kerk vaarwel zeiden. En het geldt evenzeer voor de islamitische hervormers van nu, die niets moeten hebben van de volksislam met zijn heiligen en ronduit minachting koesteren voor de oelama, het traditionele gilde van schriftgeleerden.

De vergelijking tussen de politieke islam en de protestantse hervormingsbeweging van de vroegmoderne tijd roept de vraag op hoe in beide gevallen 
over het recht van opstand wordt gedacht. ${ }^{5}$ Zowel het christendom als de islam leert gehoorzaamheid aan het door God gegeven gezag en daarom moet opstand in beide gevallen uitdrukkelijk worden gelegitimeerd. Dat is in beginsel vrij eenvoudig. Men hoeft slechts aan te tonen dat het zittende regime niet het ware geloof aanhangt en daarom onwettig is. Daarmee is de heerser ontmaskerd als een tiran en mag, nee moet hij zelfs worden weggejaagd. De vraag is alleen wie bevoegd is tot dit oordeel. Kan elke willekeurige burger zich hierover uitspreken of is dat slechts voorbehouden aan religieuze en politieke vertegenwoordigers? Over deze vraag bestond in het zestiende-eeuwse christendom al veel verwarring en het lijkt er op dat dit in de islamitische wereld van nu niet anders is.

Kijken we bijvoorbeeld naar de Nederlandse opstand tegen Filips II, dan zien we dat het recht van gewapend verzet in de eigentijdse pamfletliteratuur aan iedere burger afzonderlijk werd toegekend. Maar dat was niet de opvatting die uiteindelijk de overhand zou krijgen. Hollandse regenten zoals Oldenbarnevelt, Hooft en Vrancken waren beducht voor te veel invloed van de burgerij en omarmden daarom de aristocratische opstandsleer van Franse hugenoten, die onder andere was te vinden in de Francogallia (1573) van François Hotman en de Vindiciae contra Tyrannos (1579) van Junius Brutus alias Philippe du Plessis Mornay. ${ }^{6}$ Deze monarchomachen of tirannenbestrijders verdedigden een soort constitutionalistische theorie die gebruik maakte van het privaatrechtelijke contractbegrip. Volgens deze theorie zou de vorst een overeenkomst hebben met het volk als georganiseerde rechtspersoon, dat wil zeggen de standenvertegenwoordiging of statenvergadering. De bedoeling van de redenering is duidelijk: wanneer de vorst zijn boekje te buiten ging zouden de lagere magistraten of ephoren, zoals de calvinisten plachten te zeggen, het recht hebben hem af te zetten.

Deze constitutionalistische theorie ging terug op de conciliaire beweging, die tijdens het concilie van Konstanz (1417-1418) tevergeefs had geprobeerd de paus te onderwerpen aan de invloed van de bisschoppen. De monarchomachen waren dus niet bepaald origineel. Zij putten uit dezelfde middeleeuwse bronnen die de jezuïeten in dezelfde tijd gebruikten om het katholieke verzet

5 De vergelijking met het protestantisme is een bekend thema van de antropoloog-filosoof Ernest Gellner. Zie ook van de antropoloog Dale F. Eickelman, 'Inside the Islamic reformation', Wilson Quarterly, 22-1 (1998), p. 80-90.

6 M. van Gelderen, The political thought of the Dutch Revolt, 1550-1590 (Cambridge 1992) 269-275. Zie ook F. Postma, 'Het ontstaan van het Nederlandse Statenbewind', Bijdragen en Mededelingen betreffende de Geschiedenis der Nederlanden, 120 (2005), p. 363-378. 
tegen protestantse vorsten aan te moedigen. Wanneer we de traditie tot de bron volgen, komen we uit bij het aristotelisme, dat vooral dankzij vertalingen van de twaalfde-eeuwse Spaans-Arabische filosoof Ibn Rushd of Averroës in het westen bekend was geworden. Het gaat dan vooral om de gedachte dat de politieke gemeenschap een natuurlijk gegeven is. Hierop valt het volgende syllogisme te baseren. De mens heeft als 'zoön politikon' natuurlijke rechten en plichten ten opzichte van zijn medemensen. Aangezien de vorst ook een mens is, kunnen we concluderen dat hij natuurlijke verplichtingen heeft tegenover zijn onderdanen, zoals een vader deze heeft tegenover zijn kinderen. Hier lag het aanknopingspunt voor de latere leer van het regeringscontract.

In de islamitische wereld bestaat momenteel ook verwarring over de vraag wie tegen wie in opstand mag komen. De oelama zien zich zelf vanouds als de spreekbuis van de gelovigen en als de aangewezen instantie om te oordelen over de sharia, het islamitische rechtsstelsel. Maar het gezag van deze schriftgeleerden is in de loop van de vorige eeuw uitgedaagd door aanhangers van de politieke islam, die vinden dat er te weinig wordt ondernomen tegen interne en externe bedreigingen van het geloof. Een invloedrijke ideoloog was bijvoorbeeld de Egyptenaar Sayyid Qutb, die in 1966 werd opgehangen op beschuldiging van betrokkenheid bij een moordaanslag op Nasser door de Moslim Broederschap. Zijn ideeën klinken duidelijk door in recente geschriften die de individuele moslim oproepen tot een heilige oorlog tegen de vijanden van de Islam. Twee voorbeelden zijn De Verwaarloosde Plicht van Mohammed Faraj, waarin de moord op de Egyptische president Saddat in 1981 door de Moslim Broederschap wordt gerechtvaardigd, en de Jihad tegen Joden en Kruisvaarders die Osama Bin Laden als fatwa presenteerde in 1998 . $^{7}$

Het voert te ver om hier uitgebreid in te gaan op de islamitische ideeën over de rechtvaardiging van gewapend verzet tegen buitenlandse veroveraars en afvallige heersers. Over die afvallige heersers moet echter wel iets gezegd worden. Islamitische geestelijken zijn altijd voorzichtig omgesprongen met het tot ongelovige verklaren van andere moslims (takfier), maar er is een belangrijk precedent waarop hedendaagse fundamentalisten zich veelvuldig beroepen. Het moet worden gesitueerd in de dertiende eeuw, toen de Mongo-

7 De Nederlandse arabist J.J.G. Jansen gaf dit geschrift uit onder de titel The Neglected Duty: The Creed of Sadat's Assassins and Islamic Resurgence in the Middle East (New York en Londen 1986). De tekst van Osama Bin Laden is te vinden op de website van Federation of American Scientists onder de titel Jihad Against Jews and Crusaders, http://www.fas.org/irp/world/para/docs/980223-fatwa.htm (bezocht 20 dec. 2005) 
len het Midden-Oosten veroverden en een einde maakten aan het kalifaat van Bagdad. Voor de moslims waren zij vreemde overheersers en mochten ze dus bestreden worden, maar de zaak werd ingewikkeld toen Ghazan, de koning van de Mongolen, zich kort voor 1300 tot de islam bekeerde. Dit leek gewapend verzet onmogelijk te maken, maar de beroemde Syrische filosoof Ibn Taymiyya zag toch een aanleiding om 'het takfier van de heerser' uit te spreken. Ghazan had namelijk zijn soldaten geen gehoorzaamheid aan de sharia opgelegd. Hij onderhield een 'gemengd regime' en kon daarom worden ontmaskerd als een ongelovige.

Sprak het voor Ibn Taymiyya nog vanzelf dat de veroordeling van een wereldlijk heerser een zaak van de religieuze leiders was, voor degenen die zich tegenwoordig op hem beroepen geldt die beperking niet meer. Het 'takfierisme' is een ongeorganiseerde vorm van verdachtmaking geworden, die zich niet alleen meer richt tegen politieke leiders maar tegen allerlei mensen die als een bedreiging voor het ware geloof worden gezien. Ook de brief die Mohammed B. aan het lichaam van Theo van Gogh vaststak bevat volgens Jansen elementen van de takfier-ideologie. ${ }^{8}$ Het is opvallend dat de religieuze autoriteiten, met voorop de sjeik van de al-Azhar universiteit in Caïro, niet duidelijker stelling nemen tegen dit ongeorganiseerde geweld. Zij veroordelen weliswaar terroristische acties, maar hoofdzakelijk op grond van het feit dat er disproportioneel veel geweld wordt toegepast en slachtoffers worden gemaakt onder weerloze burgers. Dat druist in tegen de islamitische regels voor een 'eerlijke strijd'. Maar de competence de guerre van de zelfbenoemde jihadstrijders wordt niet openlijk ter discussie gesteld en bestreden. ${ }^{9}$

Hoewel de christelijke en islamitische ideeën over het recht van gewapend verzet zich moeilijk laten vergelijken, lijkt toch een belangrijk verschil te zijn dat de islamitische traditie geen constitutionalistische theorie zoals die van de monarchomachen kent. Een verklaring hiervoor zou kunnen zijn dat het aristotelisme in de Arabische wereld nooit meer is hersteld van de harde klappen die Al Ghazali en Ibn Taymiyya er aan toe brachten in respectievelijk de elfde en dertiende eeuw. We kunnen speculeren over de gevolgen hiervan voor de ontwikkeling van het islamitische politieke denken, maar

8 Hans Jansen, 'Takfir' Trouw (Letter en Geest) 9 juli 2005, p. 2-3.

9 Zie bijvoorbeeld John Kelsay, 'Arguments concerning resistance in contemporary Islam', $46 \mathrm{pp}$ http://www.fsu.edu/ religion/faculty/documents/resistance.pdf (bezocht $20 \mathrm{dec}$ 2005), p. 24: '...the al-Azhar critique focuses less on The Neglected Duty's claim that a vanguard has authority to fight than on the question of whether armed resistance will violate the norms of honorable combat.' 
misschien is het nuttiger om te letten op de overeenkomsten met het traditionele politieke denken in Europa. Het grote manco van zowel de christelijke als de islamitische ideeën over een gerechtvaardige opstand is namelijk het ontbreken van een duidelijke definitie en plaatsbepaling van de politieke macht. Daardoor waren en zijn alle pogingen om deze macht vanuit de religie te beperken tot mislukken gedoemd. Dit laat zich het beste verduidelijken aan de hand van Thomas Hobbes, die als grondlegger van de moderne staatsgedachte kan worden beschouwd.

\section{De moderne staat}

Thomas Hobbes werd geboren in 1588, het jaar van de Spaanse Armada, die niet alleen Nederland maar ook Engeland bedreigde. Hij schreef zelf later dat zijn moeder in dat jaar een tweeling baarde, 'myself and fear'. Zijn leven stond in het teken van de godsdienstige burgeroorlog die Engeland teisterde in de eerste helft van de zeventiende eeuw en dat deed hem besluiten een politieke theorie te ontwerpen die een definitieve burgervrede garandeerde. Het belangrijkste resultaat hiervan was de Leviathan die in 1651 verscheen. De titel van het boek verwijst naar het Bijbelboek Job, waarin sprake is van een gelijknamig monster dat Gods almacht symboliseert. Hobbes paste deze naam toe op de staat, die hij een 'mortal God' noemde. Hij zinspeelde hiermee op de traditionele gedachte dat mensen alleen in vrede met elkaar kunnen leven, wanneer zij 'in de vreze des Heren wandelen'. Omdat deze waarheid kennelijk niet meer opging, zouden mensen volgens hem zelf een hogere macht moeten creëren, een soeverein die het monopolie op geweld zou bezitten.

Hobbes zag de opstandsleer van zowel protestanten als katholieken als het grote probleem van zijn tijd en hij besefte dat dit probleem radicaal, bij de aristotelische wortel moest worden aangepakt. Zolang men uitging van de gedachte dat het volk een natuurlijk gegeven is waarmee de vorst heeft rekening te houden, zou er weinig van 'law and order' terecht komen. De vorst zou aan het gewoonterecht gebonden blijven en niet in staat zijn eigen wetten op te leggen aan twistzieke godsdienstfanatici. Alleen absolute macht kon uitkomst bieden. Maar welke legitimatie kon hiervoor worden gevonden? Hoe viel aannemelijk te maken dat mensen zich uit vrije wil aan zo'n macht zouden onderwerpen?

Hobbes begreep dat deze vraag logischerwijs een gezagloze of anarchistische beginsituatie veronderstelt. Dit is de zogenaamde 'state of nature', 
waarin één natuurlijk recht bestaat, namelijk het recht op zelfbehoud. De natuurlijke, op gezinsverbanden gebaseerde samenleving van Aristoteles maakt zo in Hobbes' theorie plaats voor een individualistische natuurtoestand, waarin een oorlog heerst van allen tegen allen. Omdat zelfbehoud op den duur onmogelijk zou zijn in deze omstandigheden, rest er voor de individuen in de natuurstaat geen andere oplossing dan een convenant te sluiten, waarbij iedereen zijn recht op geweld afstaat aan een nieuw in te stellen soevereine instantie. Dit is het zogenaamde sociale contract, dat aan de basis ligt van de 'civil state' en dat wezenlijk verschilt van het eerder genoemde regeringscontract omdat het geen afspraak behelst tussen vorst en volk maar tussen individuen onderling.

In de nieuwe staat die Hobbes voor ogen stond heeft de soeverein het wapenmonopolie, dat hij inzet voor de handhaving van rust en orde. Mocht hij falen in zijn taak, dan heeft elk individu het recht om het contract te verbreken. Men zou een opstand kunnen beginnen, maar dat leek Hobbes niet waarschijnlijk omdat de maatschappij dan weer zou afglijden naar de afschrikwekkende natuurstaat. Emigreren zou een betere oplossing zijn en anders restte slechts gehoorzaamheid. Het meest reële gevaar zou nog verdeeldheid binnen het soevereine machtscentrum zelf kunnen zijn. Daarom voelde Hobbes weinig voor een absolute aristocratie of een absolute democratie, maar zijn theorie sluit deze vormen in beginsel niet uit. Misschien klinkt het allemaal wat kunstmatig in moderne oren, maar Hobbes kwam tenslotte uit waar hij wilde zijn, namelijk bij de conclusie dat de soeverein op geen enkele wijze gebonden kan zijn aan een contract met het volk, omdat er zonder hem eenvoudig geen volk zou zijn.

De historische betekenis van de Leviathan moet niet worden gezocht in de uitbreiding van de moderne staatsmacht maar in de beperking ervan. Juist omdat Hobbes zo'n scherpe definitie en plaatsbepaling van de soevereiniteit gaf, stelde hij latere denkers als Locke en Montesquieu in staat om na te denken over een constitutionele beperking hiervan. De ironie van zijn extreme absolutisme is dus, dat het de weg baande voor het moderne liberale constitutionalisme. Dit moderne constitutionalisme nam wel bepaalde elementen over uit de traditie maar was toch iets wezenlijks nieuws. De zwakte van de traditionele leer was, dat zij reactief en negatief was. De monarchomachen verzetten zich tegen de opkomst van de moderne, gecentraliseerde staatsmacht zonder een alternatief te kunnen bieden. En omdat zij niet in staat waren duidelijk aan te geven wat die macht inhield en bij wie zij uiteindelijk berustte, konden zij ook niet duidelijk aangeven welke grenzen er aan moesten worden gesteld. Nadat ze Filips II in 1581 als vorst hadden 
afgezworen hadden de Nederlanders een eeuw nodig om er achter te komen in wat voor soort staat zij nu eigenlijk leefden. Pas in de tijd van Johan de Witt slaagden theoretici er mede dankzij het werk van Hobbes in om vast te stellen dat het resultaat van de Opstand een republiek met een absolute aristocratie was. ${ }^{10}$

Een andere belangrijke consequentie van Hobbes' theorie was, dat geweten en recht uit elkaar getrokken werden. Met de gedachte aan een natuurlijke samenleving gaf Hobbes ook de gedachte aan een natuurlijke religie en moraal op. Religie en moraal ontstaan volgens hem pas wanneer mensen zich in een 'civil state' tot een volk hebben verenigd. Dit betekent dat het positieve recht niet langer onderworpen is aan een goddelijk of natuurlijk recht (met uitzondering dan van dat ene natuurlijke recht op zelfbehoud). In de 'civil state' is dan ook geen plaats meer voor onderdanen die met een beroep op hun geweten inbreuk maken op de publieke rechtsorde. Daar staat tegenover dat de soeverein niets meer heeft te maken met het zielenheil van zijn onderdanen. Geloof en moraal behoren tot het terrein van de particuliere gezindte en daar kan het recht geen inbreuk op maken.

Het oude kerkrechtelijke onderscheid tussen forum internum en forum externum kreeg zodoende een nieuwe betekenis. Het was oorspronkelijk bedoeld om vast te stellen welke zaken in de biecht moesten worden afgehandeld en welke voor de kerkelijke rechtbank dienden te verschijnen. Maar in de zeventiende eeuw werd het in meer algemene zin gebruikt voor het definiëren van de private en publieke sfeer, waarmee de grondslag werd gelegd voor het onderscheid tussen kerk en staat. Dit was een zeer ingrijpende verandering, omdat de godsdienst hierdoor tot een individuele aangelegenheid werd gemaakt. Voor protestanten was dat misschien niet zo'n probleem, maar voor katholieken lag dat anders omdat zij gewend waren aan een vanzelfsprekende verwevenheid van de godsdienst met allerlei andere aspecten van het maatschappelijke leven. Voor moslims, die veel waarde hechten aan de oemma of wereldwijde islamitische gemeenschap, is dit individualisme ook moeilijk te aanvaarden. De aanpassing aan de Nederlandse maatschappij brengt voor hen dan ook ingrijpende veranderingen met zich mee. Zo wordt een 'verinnerlijking' van het geweten geëist, die in Europa zelf pas door een zeer geleidelijke cultuurverandering tot stand is gekomen. Die aanpassing geeft natuurlijk problemen en daarom moet naast alle repressieve maatregelen die op het ogenblik worden genomen ook een preventief beleid

10 E.H. Kossmann, Politieke theorie in het zeventiende-eeuwse Nederland. Verhandelingen der Koninklijke Nederlandse Akademie van Wetenschappen, N.R., dl. 67, no. 2. Afdeeling Letterkunde (Amsterdam 1960). 
worden gevoerd dat jonge moslims ervan weerhoudt naar hun geweten te handelen. 